\title{
Tibial nerve stimulation with a miniature, wireless stimulator in chronic peripheral neuropathic pain
}

This article was published in the following Dove Press journal:

Journal of Pain Research

15 March 2017

Number of times this article has been viewed

\author{
Paweł Sokal' \\ Marek Harat ${ }^{2}$ \\ Piotr Zieliński ${ }^{3}$ \\ Sara Kierońska' \\ 'Department of Neurosurgery, \\ Military Research Hospital, \\ Bydgoszcz, ${ }^{2}$ Department of Public \\ Health, Ludwik Rydygier Collegium \\ Medicum, Bydgoszcz, Nicolaus \\ Copernicus University, Toruń, \\ ${ }^{3}$ Department of Sports Medicine, \\ University of Physical Education and \\ Sport, Gdansk, Poland
}

\begin{abstract}
Peripheral neuropathic pain (PNP) and complex regional pain syndrome (CRPS) can be effectively treated with peripheral nerve stimulation. In this clinical trial report, effectiveness of novel, miniature, wirelessly controlled microstimulator of tibial nerve in PNP and CRPS was evaluated. In this pilot study the average preoperative visual analog scale (VAS) score in six patients was 7.5, with 1,3 and 6 months: $2.6(p=0.03), 1.6(p=0.03)$, and $1.3(p=0.02)$, respectively. The mean average score in the six patients a week preceding the baseline visit was 7.96, preceding the 1,3 and 6 month visits: 3.32 ( $p=0.043), 3.65(p=0.045)$, and $2.49(p=0.002)$, respectively. The average short-form McGill pain score before surgery was 23.8 , and after 1 , 3 and 6 months it was $11.0(p=0.45), 6.3(p=0.043)$, and $4.5(p=0.01)$, respectively. Applied therapy caused a reduction of pain immediately after its application and clinical improvement was sustained on a similar level in all patients for six months. No complications of the treatment were observed. Intermittent tibial nerve stimulation by using a novel, miniature, wirelessly controlled device can be effective and feasible in PNP and CRPS. It is a safe, minimally invasive, and convenient neuromodulative method.
\end{abstract}

Keywords: tibial nerve stimulation, peripheral nerve stimulation, miniature stimulator, peripheral neuropathic pain, complex regional pain syndrome

\section{Background}

Peripheral nerve stimulation (PNS) belongs to the least invasive neuromodulative procedures approved for the treatment of neuropathic pain. PNS requires surgical exposure of the target nerve or percutaneous implantation of a cylindrical electrode in the vicinity of the stimulated nerve and can be applied in experienced centers. Stimulation of peripheral nerves produces paresthesia in the area innervated by this nerve and induces analgesic effect in several mechanisms: peripheral, spinal segmental and central. ${ }^{1}$ The most common indications are neuropathic pain related to the dysfunction of certain nerve, that is, occipital neuralgia, infra- or supraorbital trigeminal neuropathic pain, inquinal pain after herniorrhaphy, postherpethic neuralgia, and complex regional pain syndrome (CRPS). ${ }^{2-9}$

Peripheral neuropathic pain (PNP) is defined as the presence of painful symptoms due to peripheral nerve dysfunction. PNP can be caused by trauma, infection, diabetes, alcohol abuse, cancer chemotherapy, and vitamin deficiency. Diabetes mellitus is the most common cause of PNP. Approximately up to $50 \%$ patients with diabetes develop neuropathy and half of them have pain as a main symptom. ${ }^{10}$ People usually have chronic, painful symptoms in their feet and hands. For its management, varying
Department of Neurosurgery, The 10th Military Research Hospital, Powstancow Warszawy Street 5, 85-68I Bydgoszcz, Poland

Tel +48 26I 417093

Fax +48261417094

Email psokal@wp.pl 
drug combinations (nonsteroidal anti-inflammatory drugs, antidepressants, and antiepileptic drugs), exercise, diet, and physiotherapy are available. Current treatments are frequently insufficient.

PNP can be treated with the neurostimulation: spinal cord stimulation (SCS), dorsal root ganglion stimulation (DRGS), or PNS. ${ }^{11-14}$ SCS is the best documented efficient neuromodulative method in painful diabetic peripheral neuropathy (PDPN). ${ }^{12} \mathrm{SCS}$ is more efficient in diabetic peripheral neuropathic pain and causalgia than in intercostal and postherpetic neuralgia. ${ }^{15}$ According to the Neuromodulation Appropriateness Consensus Committee, SCS seems to be an efficacious and feasible treatment for intractable PDPN with recommendation to introduce in it the early stage of therapeutic management. ${ }^{16}$ CRPS with the distribution in legs is also a classical indication for SCS. ${ }^{16-18}$

Tibial nerve stimulation is indicated in patients with PNP located in foot. The stimulation can also be used in bladder disorders. Several reports also proved efficacy of this stimulation in overactive bladder syndrome. ${ }^{19-21}$

The objective of the study was to evaluate BlueWind System safety and performance which serves for tibial nerve stimulation in patients with PNP. Based on the experience of our center, we wanted to present our comments on the usability of this novel neuromodulation system.

\section{Methods}

We report a prospective clinical trial study on the effects of PNS in PNP of a different origin treated with tibial nerve stimulator in Department of Neurosurgery in Bydgoszcz, Poland, in years 2014-2015. The study was part of a trial conducted in four centers in Europe (two in Poland and two in Belgium) and one center in Israel. The trial was sponsored by BlueWind Medical Ltd., Israel producer of the Reprieve System. The study was registered in ClinicalTrial.gov under identifier NCT02209896. The Ethics Committee at Military Medical Institute, Warsaw, Poland, approved the study protocol on February 28, 2014. The study was conducted in accordance with local regulations, good clinical practice guidelines, and the Declaration of Helsinki. All patients provided a written consent.

\section{Patient selection}

The patients were recruited according to the following inclusion criteria: signed informed consent, male or female aged 18-80 years, diagnosis of chronic neuropathic pain due to neuropathy for at least 6 months demonstrated by 3 ratings per day across 7 days, patient refractory to conservative treatments for at least 6 months, and stable pain medication for at least 4 weeks prior to study enrollment. Exclusion criteria included the following: previous participation in the study within the past 90 days, any active implant (cardiac or other), current pregnancy, any clinically significant neurologic disorder, any clinically significant or unstable psychiatric condition or cardiovascular, pulmonary, gastrointestinal, hematological, hepatic, renal or endocrine disease, and severe peripheral vascular disease causing ischemic ulcers. Table 1 presents the characteristics of patients enrolled to the study in our center.

\section{Study design}

The study consisted of the following stages: the first visitrecruitment; the second visit-compatibility test; the third visit-implantation; the fourth visit after 1 month-activation of system and parameter setting; and follow-up visits-1, 3, and 6 months post activation.

At Visit 1, each patient signed an informed consent form (ICF). The patient was also asked to fill-in a daily pain diary for a period of seven consecutive days before the second visit.

At Visit 2, post recruitment eligible patients had appointment and were given compatibility tests with stimulation leads (e.g., needle electrodes) inserted temporary into the patient's lower leg in proximity to the tibial nerve and individual stimulation were set for pain relief. Intermittent stimulation with a frequency of up to $40 \mathrm{~Hz}$, a pulse width of up to $800 \mu \mathrm{s}$, and a current up to $18 \mathrm{~mA}$ was given for a period of 30 minutes.

Individual stimulation parameters for an effective pain relief were set; optimal stimulation parameters were determined for each patient according to their sensations and pain severity. Success of the compatibility test assessed as a 3-point reduction in visual analog scale (VAS) between the baseline pain and the average of the treatment pain plus post

Table I Characteristics of patients $\mathrm{N}=6$

\section{Patient Characteristics}

Patient I Female, 39 years old, diabetic PNP with diabetes since 2009, symmetrical feet pain paresthesias, and burning sensation in soles

Patient 2 Female, 62 years old with PNP in soles and toes after boreliosis in 2012

Patient 3 Male, 76 years old, idiopathic PNP: tingling and sharp sensation in sole and heel of left leg for 20 years

Patient 4 Male, 78 years old, idiopathic PNP of left leg with tingling in heel and sole

Patient 5 Male, 46 years old, spinal cauda equina injury after trauma due to motorbike accident in 1989 with CRPS and after failed SCS trial

Patient 6 Male, 55 years old, diabetic PNP lasting 4 years with diabetes in both feet with the predominance on the right side

Abbreviations: CRPS, complex regional pain syndrome; PNP, peripheral neuropathic pain; SCS, spinal cord stimulation. 
treatment pain. Only patients who passed the compatibility test proceeded to the implantation phase. At Visit 3, the implantation of the device was performed in an operating theatre under local anesthesia.

At Visit 4, activation of the BlueWind Reprieve System was performed in all patients 1 month after the implantation. During the activation process, individual stimulation parameters were set gradually to minimize patient discomfort until optimal settings were achieved. Stimulation parameters are presented in Table 2.

Each patient attended the clinic at 1, 3, and 6 months after system activation. The patients were asked about their symptoms, discomforts that might have been felt, or other physiological or technical problems that might have arisen. Every adverse event was recorded in the patient's case report form. Tuning of stimulation parameters was performed if required. Any change in medications or dosage was recorded.

The primary study endpoints were as follows: pain assessment by VAS at 6 months post activation as compared to baseline and serious adverse event (SAE) incidence; the secondary endpoints were as follows: pain-related medication consumption/day, short-form (SF)-McGill pain questionnaire and quality of life questionnaire SF-36 health survey and safety. Measurements of pain were conducted by using the patient diary (recording the VAS three times per day across 7 days), the SF-McGill pain questionnaire, and the quality of life questionnaire SF-36.

\section{Procedure}

Implantation was performed under local anesthesia. A $5 \mathrm{~cm}$ long skin incision line was carried out proximal to the point located $3 \mathrm{~cm}$ over the medial malleolus and $2 \mathrm{~cm}$ posterior to the tibia. After exposing crural fascia, the neurovascular tibial bundle was identified. A correct implant orientation was essential so that the exposed electrodes faced the tibial nerve in direct contact. The device was secured with four sutures to the fascia 1-2 cm deep under the skin which was closed with subcutaneous and cutaneous sutures (Figure 1).

Table 2 Parameters and duration of stimulation

\begin{tabular}{lllll}
\hline Patient & Rate (Hz) & $\begin{array}{l}\text { Pulse width } \\
(\boldsymbol{\mu s})\end{array}$ & $\begin{array}{l}\text { Amplitude } \\
(\mathbf{m A})\end{array}$ & $\begin{array}{l}\text { Duration time } \\
\text { (hour/24 hours) }\end{array}$ \\
\hline Patient I & 20 & 800 & $4.4-4.8$ & 2 \\
Patient 2 & $10-20$ & $500-800$ & $3.7-4.7$ & $\mathrm{I}$ \\
Patient 3 & 20 & 800 & 4.7 & $\mathrm{I}$ \\
Patient 4 & 20 & 100 & $2.3-3.1$ & 0.5 \\
Patient 5 & 20 & 800 & 8.5 & 2.5 \\
Patient 6 & $10-20$ & $800-200$ & 8.5 & $\mathrm{I}$ \\
\hline
\end{tabular}

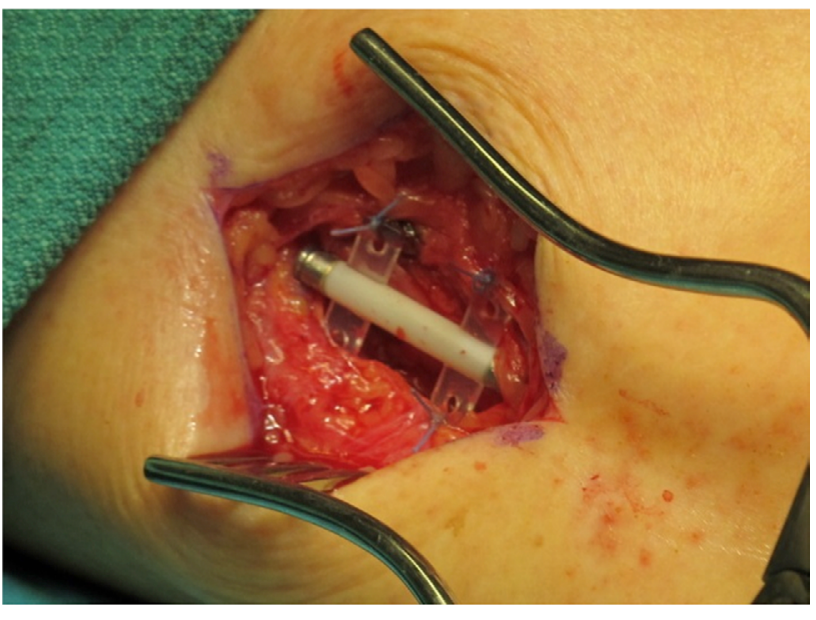

Figure I Implant fixed to fascia over the tibial nerve in patient 3.

\section{Device description}

The BlueWind Reprieve system is a neurostimulator consisting of implantable component (the implant), external control unit, and physician programmer. The implant is a miniature, wireless device which serves for PNS. It is implanted next to the tibial nerve.

The device is powered wirelessly from a wearable unit that also controls stimulation parameters and records diagnostic information for the use of treating physician (Figure 2). The patient can control the stimulation schedule and the intensity. A physician tablet programmer can define stimulation parameters and read diagnostic information stored on the device.

\section{Statistical analysis}

All statistical analyses were performed using Statistica version 10 (StatSoft) and Microsoft Excel 2007. The distribution of results differed from the normal distribution, the correlation analysis of the data was performed, and the comparative studies were analyzed statistically using the

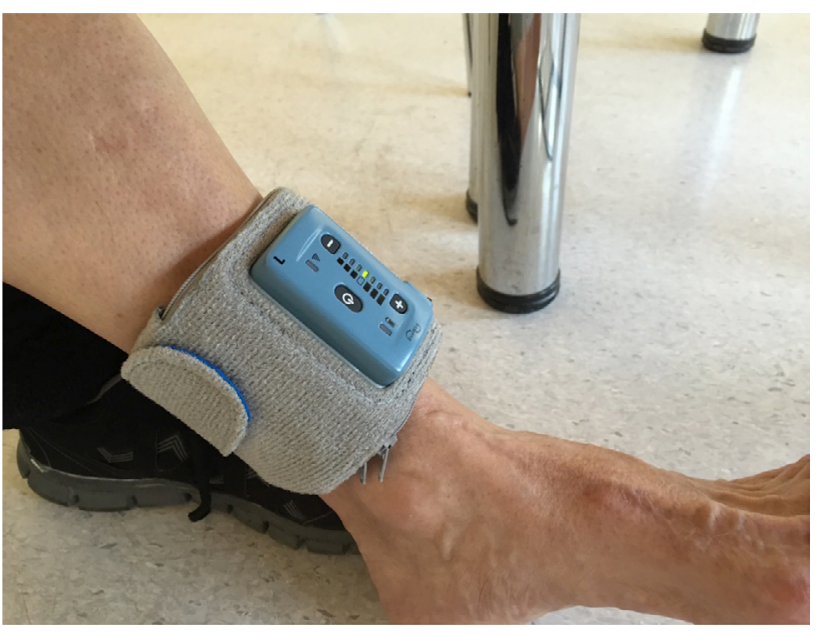

Figure 2 External control unit on patient's leg. 
nonparametric analysis of variance Friedman test. To confirm the significance of differences between related variables, the Dunn multiple comparison test was used. The $p$-value $<0.05$ was considered statistically significant.

\section{Results}

In this pilot study, the follow-up was 6 months in six patients, the average preoperative VAS score was 7.5, after 1 month was $2.6(p=0.03)$, after 3 months was $1.6(p=0.03)$, and after 6 months was 1.3 ( $p=0.02$; Figure 3 ). The mean average score in six patients during a week preceding baseline visit was 7.96, preceding 1 month visit $3.32(p=0.043)$, preceding 3 months visit 3.65 ( $p=0.045)$, and preceding 6 months visit 2.49 ( $p=0.002$; Table 3 and Figure 4). Average McGill score before surgery was 23.8 , after 1 month $11.0(p=0.45)$, after 3 months $6.3(p=0.043)$, and after 6 months $4.5(p=0.01$; Figure 5). Applied therapy caused reduction of pain immediately after its application and therapeutic effect was observed in the first and third months till the sixth month on a similar level in all patients. No complications of the treatment or with the wound

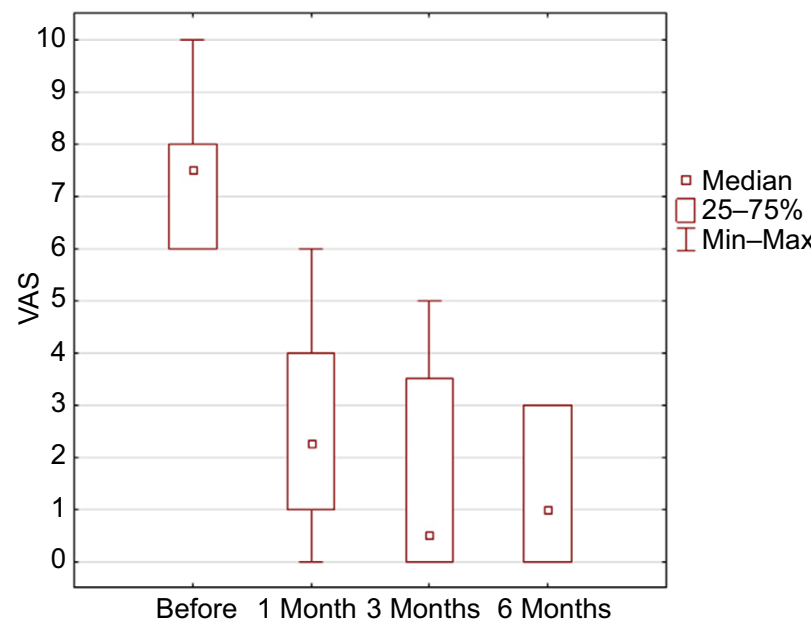

Figure 3 Results in VAS scale in control visits $p=0.0023$ using ANOVA Friedman test. Abbreviations: ANOVA, analysis of variance; VAS, visual analog scale.

Table 3 Mean averages of 21 measurements of VAS taken three times a day during a week according to patients' diaries preceding control visit before surgery, after I month, after 3 months, and after 6 months in the treated leg

\begin{tabular}{lllll}
\hline Patient & Before & I month & 3 months & 6 months \\
\hline Mean & 7.96 & 3.32 & 3.65 & 2.49 \\
Patient I & 8.19 & 4.71 & 2.86 & 2.25 \\
Patient 2 & 8.09 & 3.28 & 6.6 & 5.68 \\
Patient 3 & 6.60 & 3.00 & 4.76 & 2.0 \\
Patient 4 & 7.35 & 1.71 & 3.0 & 1.28 \\
Patient 5 & 9.76 & 0.95 & 1.62 & 1.33 \\
Patient 6 & 7.76 & 6.28 & 3.05 & 1.19 \\
\hline
\end{tabular}

Abbreviation: VAS, visual analog scale.

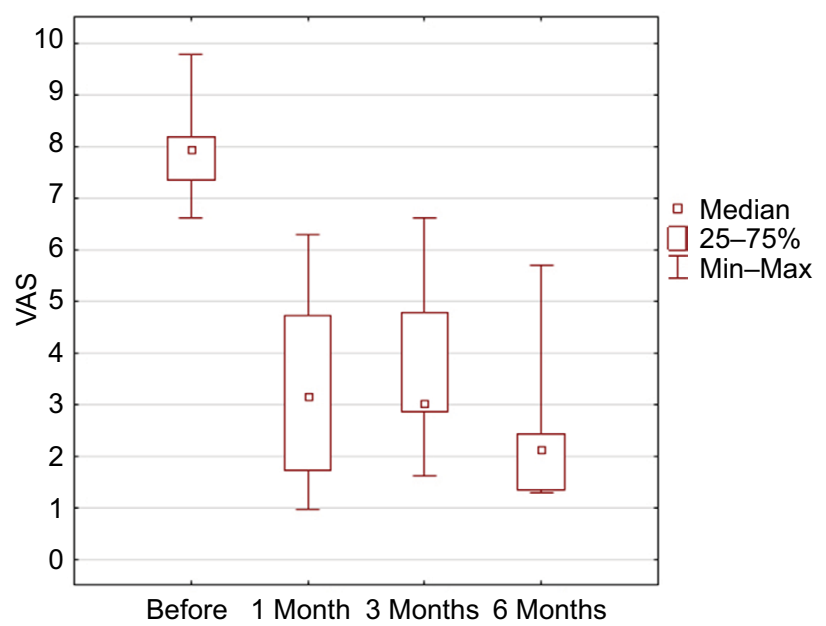

Figure 4 Results in mean VAS during the week preceding the controlled visit $(p=0.0003)$ in ANOVA Friedman test.

Note: Statistical significance observed after I month; after 3 months, $p=0.03$; and after 6 months, $p=0.02$ in Dunn's multiple comparison.

Abbreviations: ANOVA, analysis of variance; VAS, visual analog scale.

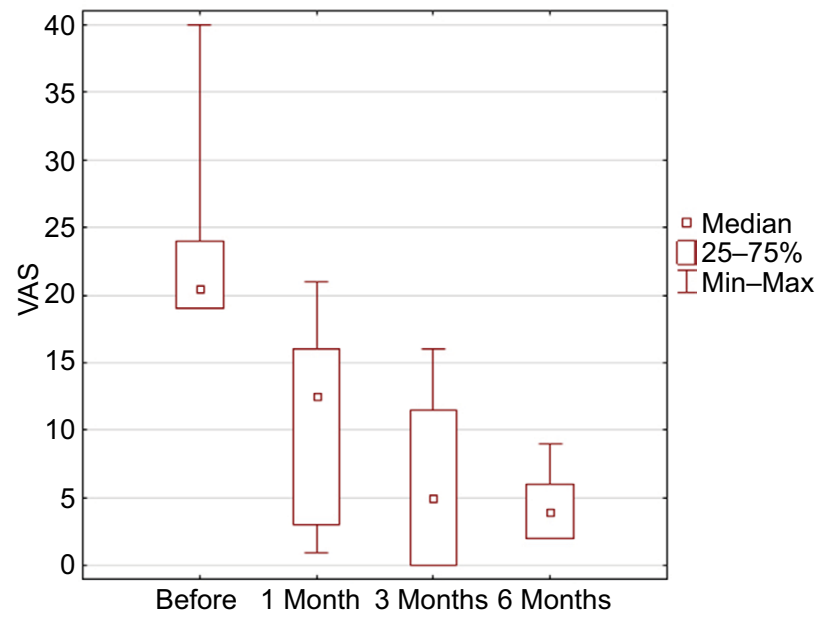

Figure 5 Results in McGill score ( $p=0.0023$ in ANOVA Friedman test).

Note: Statistical significance after 3 months and after 6 months.

Abbreviations: ANOVA, analysis of variance; VAS, visual analog scale.

healing were observed. In one patient (patient 6), one side effect of the stimulation of the tibial nerve was noted. The patient complained of swelling of the treated foot during the active stimulation although the analgesic effect was sustained.

\section{Discussion}

We report results of the multicenter study on the effectiveness of miniature tibial nerve stimulator implant based on experience and results of one center. This is a case series consisting of six patients. This is the first report on the feasibility and efficacy of this minimally invasive, neuromodulative procedure. After the straightforward device implantation, patients do not have trial stimulation. In this procedure, the trial stimulation takes place before the implantation and is replaced by 
external stimulation of the tibial nerve by a needle electrode lasting 30 minutes during the so-called compatibility test. In our center, from seven patients one had to be excluded due to failed compatibility test caused by too small pain reduction ( $<3$ points on VAS score between baseline and after treatment pain). Activation of the implant was carried out 1 month after the implantation. Parameters were set to cover the area of pain (usually sole of the foot, heel, toes, or cnemis) with paresthesia and thus reduce the pain. In our group, satisfying pain relief was observed in all treated cases. The origin of pain in these patients was located distally to the implantation site. Explanation of the positive response on stimulation can be explained by Wall and Melzack theory concerning PNS which says that stimulation of $\mathrm{C}$ fibers activates cell in dorsal horns and reduces pain transmission. ${ }^{22}$ Several reports proved effectiveness of PNS in different pain disorders. ${ }^{3,12,23,24}$ In our series, in one patient (patient 5), the origin of neuropathic pain was different and source of neuropathic pain was located above the implantation site. This patient had CRPS type I caused by the cauda equina injury due to fracture of the lumbar spine. He had been suffering on excruciating pain located in both feet with the predominance of one leg for 7 years due to spinal roots injury caused by a motorbike accident. The pain filled the criteria of cauda equine syndrome (bladder disturbances, numbness, and muscle weakness) and CRPS type I (continuing, regional, distal pain with motor deficit and asymmetry of temperature). ${ }^{25} \mathrm{He}$ underwent a trial of SCS with a negative result 1 year before. The spectacular positive effect of tibial nerve stimulation on pain was observed in the compatibility test and remained 1 year after implantation. The source of pain comes from injured cauda equina on the level of L2. This case suggests that this kind of pain can be successfully treated with noncontinuous PNS distally to the source of pain. Thermographic effect, which reflects improved peripheral blood circulation caused by antisympathetic activity of tibial nerve stimulation, objectifies a subjective improvement expressed by the patient (Figure 6A, B).

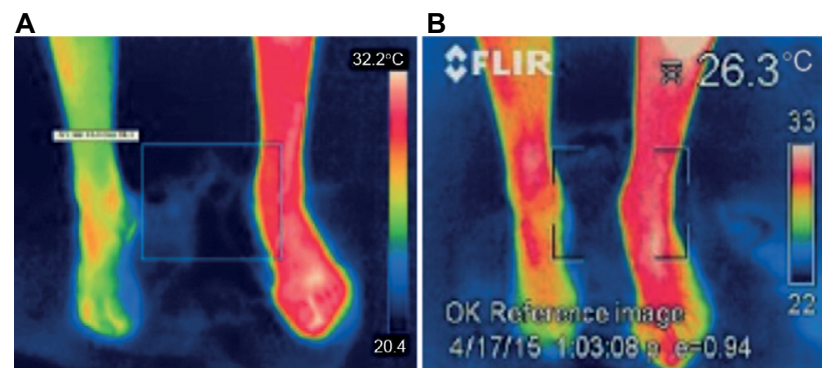

Figure 6 Thermographic effect of stimulation of the right leg in patient 5 demonstrated on the controlled visit after I month.

Note: (A) Shows both feet before stimulation and (B) after $30 \mathrm{~min}$ of stimulation.
Induced vasodilatation improves perfusion and raises warmth in stimulated leg. The mechanism of action of PNS in the suppression of sympathetic vasoconstriction may be similar to the mechanism of antisympathetic activity of SCS linked to the release of vasodilators after stimulation of fibers in dorsal root ganglia. ${ }^{26}$

The Neuromodulation Appropriateness Consensus Committee recommends SCS for the treatment of CRPS of at least 3 months duration or severe, rapidly progressing disease refractory to conservative treatment after psychological evaluation and successful trial. ${ }^{16}$ Perhaps further studies are needed to compare the effectiveness of SCS, DRGS, and PNS in CRPS and prove its efficiency in this entity. By contrast, SCS can be effective in neuropathic pain located in distal parts of lower extremities, especially when a wide range of new, multicolumn, paddle-type electrodes is available. Kumar et al in their study received $\geq 50 \%$ pain relief in $63 \%$ of the patients with PDPN after SCS at a 1-year follow-up. ${ }^{15}$ At present, DRGS seems to be a very efficient and minimally invasive tool for treatment of pain located in foot with focal distribution. ${ }^{14,27}$

Analyzing parameters and daily duration of stimulation, we noted that only 1-2 hours of active stimulation is sufficient and gives analgesic effect lasting 24 hours. The effective frequency of stimulation is low from 10 to $20 \mathrm{~Hz}$. In a whole, we do not need a large volume of charge and high current to achieve satisfactory pain control. Similarly, a significant reduction of neuropathic pain can be attained by transcutaneous electrical nerve stimulation (TENS) lasting, for instance, 20-30 minutes daily (TENS art) or even by simply grounding which is associated with charge, electrons flow, and changes of electrical potential in the extracellular environment. ${ }^{28-30}$

Intermittent and noncontinuous stimulation with average 1.4 hour/24 hours applied in the group of our patients was sufficient to ensure satisfactory improvement due to the sustained effect of neuromodulation.

Diversity of individual stimulator application was vast in our group. Patient 3 was stimulating tibial nerve from 10 to 16 times per day up to 8 hours of stimulation despite he was turning on the stimulation without evident pain aggravation. However, patient 6 was using the stimulating device once 2 weeks with session on activation lasting 30 minutes. Three patients 1, 5, and 6 noted improvement in the untreated legs. Especially, patient 5 who had the most prominent pain relief. He did not feel the paresthesia but he had alleviation of pain during the compatibility test and the treatment with concomitant $50 \%$ pain reduction in the second leg. 
Reverberi et al presented a series of patients with CRPS with PNS systems having small implantable pulse generator devices (Neuroimpulse, Lightimpulse, and Rubano) achieving reduction in pain and allodynia with substantial improvement of functioning of joints and extremities in 15 patients. In their series in three patients, implants had to be explanted due to inefficacy. ${ }^{23}$ The system that was used in this study has benefits such as minimal and leadless design, a small size, and can be placed subcutaneously using only one small skin incision. The implant does not include any energy source and therefore does not have the life span limitation. The crucial advantage of this system over standard neurostimulators is the lack of the cable-electrode leads, extensions, and lack of the large battery, which should be implanted under the skin. It ensures better comfort for patients. The implant is so small that it is impossible to palpate it under the skin and works only when the patient wants. What is new in neuromodulation and very important for the patients is the freedom of choice whether to stimulate or not to stimulate and when and how long. It all depends upon the patient.

The limitation of this study is the fact that it is a singlearm study with the small number of patients, without a control group. Further parallel group study with the control group or the cross-over study is warranted in order to confirm the efficacy of this novel nerve stimulator and provide higher level of evidence.

\section{Conclusion}

This method is minimally invasive, wireless (the lack of the cable and the lack of the large battery which should be implanted under the skin). The system fills the criteria of neuromodulative procedure, that is, reversible and easily adjustable. Wireless control is convenient for physician and not bothersome for patient. The method is safe and effective. It can be a reliable and beneficial alternative for pharmacologically treated patients with PNP and CRPS.

\section{Acknowledgments}

This study was sponsored by BlueWind Co. The authors thank the staff of BlueWind Co., especially Limor Kuznits for her support and knowledge.

\section{Author contributions}

The study was designed by BlueWind. Paweł Sokal, Sara Kierońska, Piotr Zieliński, and Marek Harat conducted the study including recruitment of patients. Data collection and data analysis were performed by Paweł Sokal and Sara Kierońska. Manuscript was prepared by Paweł Sokal with substantial intellectual input of Marek Harat and Sara Kierońska. All authors contributed toward data analysis, drafting and revising the paper and agree to be accountable for all aspects of the work.

\section{Disclosure}

The authors received payment for conduction of this study. The authors report no other conflicts of interest in this work.

\section{References}

1. Bartsch T, Goadsby PJ. Central mechanisms of peripheral nerve stimulation in headache disorders. In: Slavin KV, editor. Peripheral Nerve Stimulation. Prog Neurol Surg. Basel, Switzerland: Karger; 2011; 24:16-26.

2. Ellrich J, Lamp S. Peripheral nerve stimulation inhibits nociceptive processing: an electrophysiological study in healthy volunteers. Neuromodulation. 2005;8(4):225-232.

3. Hassenbusch SJ, Stanton-Hicks M, Schoppa D, Walsh JG, Covington EC. Long-term results of peripheral nerve stimulation for reflex sympathetic dystrophy. J Neurosurg. 1996;84(3):415-423.

4. Johnstone CS, Sundaraj R. Occipital nerve stimulation for the treatment of occipital neuralgia-eight case studies. Neuromodulation. 2006; 9(1):41-47.

5. Rodrigo-Royo MD, Azcona JM, Quero J, Lorente MC, Acín P, Azcona J. Peripheral neurostimulation in the management of cervicogenic headache: four cases report. Neuromodulation. 2005;8(4):241-248.

6. Slavin KV. Peripheral nerve stimulation for neuropathic pain. Neurology. 2011;7(2):144-148.

7. Slavin KV, Burchiel KJ. Use of long-term nerve stimulation with implanted electrodes in the treatment of intractable craniofacial pain. J Neurosurg. 2000;92:576.

8. Slavin KV, Wess C. Trigeminal branch stimulation for intractable neuropathic pain: technical note. Neuromodulation. 2005;8(1):7-13.

9. Weiner RI. Occipital neurostimulation for treatment of intractable headache syndromes. Acta Neurochir Suppl. 2007;97:129-133.

10. Huizinga MM, Peltier A. Painful diabetic neuropathy: a managementcentered review. Clin Diabetes. 2007;25(1):6-15.

11. Daousi C, Benbow SJ, MacFarlane IA. Electrical spinal cord stimulation in the long-term treatment of chronic painful diabetic neuropathy. Diabet Med. 2005;22(4):393-398.

12. Pluijms WA, Slangen RA, Joosten EA, et al. Electrical spinal cord stimulation in painful diabetic polyneuropathy: a systematic review on treatment efficacy and safety. Eur J Pain. 201;15:783-788.

13. Tesfaye S, Watt J, Benbow SJ, Pang KA, Miles J, MacFarlane IA. Electrical spinal cord-stimulation for painful diabetic peripheral neuropathy. Lancet. 1996;348(9043):1698-1701.

14. Liem L, Russo M, Huygen FJPM, et al. One-year outcomes of spinal cord stimulation of the dorsal root ganglion in the treatment of chronic neuropathic pain. Neuromodulation. 2015;18(1):41-49.

15. Kumar K, Toth C, Nath RK. Spinal cord stimulation for chronic pain in peripheral neuropathy. Surg Neurol. 1996;46(4):363-369.

16. Deer TR, Mekhail, N, Provenzano D, et al. The appropriate use of neurostimulation of the spinal cord and peripheral nervous system for the treatment of chronic pain and ischemic diseases: the neuromodulation appropriateness consensus committee. Neuromodulation. 2014; 17(6):515-550.

17. Cooney WP. Electrical stimulation and the treatment of complex regional pain syndromes of the upper extremity. Hand Clin. 1997;13(3):519-526.

18. Poree L, Krames E, Pope J, Deer TR, Levy R, Schultz L. Spinal cord stimulation as treatment for complex regional pain syndrome should be considered earlier than last resort therapy. Neuromodulation. 2013; 16(2):125-141.

19. Peters KM, Carrico DJ, MacDiarmid SA, et al. Sustained therapeutic effects of percutaneous tibial nerve stimulation: 24-month results of the STEP study. Neurourol Urodyn. 2013;32(1):24-29. 
20. Staskin DR., Peters KM, MacDiarmid S, Shore N, de Groat WC. Percutaneous tibial nerve stimulation: a clinically and cost effective addition to the overactive bladder algorithm of care. Curr Urol Rep. 2012;13(5): 327-334.

21. Surwit, EA, Campbell J, Karaszewski K. Neuromodulation of the pudendal, hypogastric, and tibial nerves with pelvic floor muscle rehabilitation in the treatment of urinary urge incontinence. Neuromodulation. 2009;12(3):175-179.

22. Melzack R, Wall PD. Pain mechanisms: a new theory. Science. 1965; 150(3699):971-979.

23. Reverberi C, Dario A, Barolat G, Zuccon G. Using peripheral nerve stimulation (PNS) to treat neuropathic pain: a clinical series. Neuromodulation. 2014:17(8):777-783.

24. Novak CB, Mackinnon SE. Outcome following implantation of a peripheral nerve stimulator in patients with chronic nerve pain. Plast Reconstr Surg. 2000;105(6):1967-1972.
25. Harden RN, Bruehl S, Perez RSGM, et al. Validation of proposed diagnostic criteria (the "Budapest Criteria") for complex regional pain syndrome. Pain. 2010;150(2):268-274.

26. Naoum JJ, Arbid EJ. Spinal cord stimulation for chronic limb ischemia. Methodist DeBakey Cardiovasc J. 2013;9(2):99-102.

27. Krames ES. The dorsal root ganglion in chronic pain and as a target for neuromodulation: a review. Neuromodulation. 2015;18(1):24-32.

28. Kılınç M, Livanelioğlu A, Yıldırım SA, Tan E. Effects of transcutaneous electrical nerve stimulation in patients with peripheral and central neuropathic pain. J Rehabil Med. 2014;46(5):454-460.

29. Johnson S, Ayling H, Sharma M, Goebel A. External noninvasive peripheral nerve stimulation treatment of neuropathic pain: a prospective audit. Neuromodulation. 2015;18(5):384-391.

30. Brown D, Chevalier G, Hill M. Pilot study on the effect of grounding on delayed-onset muscle soreness. J Altern Compl Med. 2010;16(3) $265-273$.

\section{Journal of Pain Research}

\section{Publish your work in this journal}

The Journal of Pain Research is an international, peer reviewed, open access, online journal that welcomes laboratory and clinical findings in the fields of pain research and the prevention and management of pain. Original research, reviews, symposium reports, hypothesis formation and commentaries are all considered for publication.

\section{Dovepress}

The manuscript management system is completely online and includes a very quick and fair peer-review system, which is all easy to use. Visit http://www.dovepress.com/testimonials.php to read real quotes from published authors. 